\title{
Azithromycin for Bronchial Asthma in Adults: An Effectiveness Trial
}

\author{
David L. Hahn, MD, MS, Mike Grasmick, PhD, Scott Hetzel, MS, and Steven Yale, MD, and \\ on behalf of the AZMATICS (AZithroMycin-Asthma Trial In Community Settings) Study Group
}

Background: Macrolides have antimicrobial and anti-inflammatory properties that may be useful in the treatment of chronic asthma.

Methods: We performed a randomized, placebo-controlled, double-blinded effectiveness trial of 12 weekly doses of adjunctive azithromycin, with follow-up to 1 year after randomization, in adults with persistent asthma. Measurements included overall asthma symptoms, asthma quality of life (AQL), and asthma control. Eligible subjects who declined to participate in randomization were offered enrollment into a parallel open-label (OL) azithromycin treatment arm.

Results: Of 304 adult asthma patients screened, 97 (32\%) were enrolled: 38 were randomized to azithromycin, 37 were randomized to placebo, and 22 opted in as OL subjects. OL subjects had higher rates of severe persistent asthma compared with randomized subjects $(32 \%$ vs $8 \%$, respectively; $P=.012)$. At 1 year, compared with the placebo arm, subjects randomized to azithromycin were more likely to have an $\mathrm{AQL}$ score $\geq 1$ unit increase compared with baseline, but this difference was not statistically significant $(36 \%$ vs $21 \%$ for placebo; $P=.335)$. Compared with placebo, $0 \mathrm{~L}$ subjects had significant improvements in overall asthma symptoms from baseline $(P=$ .0196), AQL $(P=.0006)$, and asthma control $(P=.0148)$.

Conclusions: Adults with asthma who were randomized to azithromycin did not show statistically significant improvement in asthma outcomes, although the study was underpowered to detect clinical improvement in 15\% (number needed to treat $=7$ ). Adults with severe persistent asthma who elected OL treatment documented clinical improvements in asthma symptoms, $\mathrm{AQL}$, and asthma control that persisted after completion of OL azithromycin (number needed to treat = 2). ( $\mathrm{J}$ Am Board Fam Med 2012;25:442-459.)

Keywords: Antibiotics; Asthma; Clinical Trials, Randomized; Infectious Diseases; Practice-based Research Networks

There is increasing interest in the therapeutic potential of macrolides in chronic asthma. A 2005 Cochrane review concluded that there was insuffi-

This article was externally peer reviewed.

Submitted 3 November 2011; revised 8 February 2012; accepted 13 February 2012.

From the Dean Clinic, Madison, WI (DLH); the Department of Family Medicine (DLH, MG) and the Department of Biostatistics (SH), University of Wisconsin, School of Medicine and Public Health, Madison; and the Department of Internal Medicine, Marshfield Clinic, Marshfield, WI (SY).

Funding: Pfizer, Inc., donated identical matching azithromycin and placebo. The Wisconsin Academy of Family Physicians; the American Academy of Family Physicians Foundation, under the auspices of the Joint Grant Awards Program; the Dean Foundation for Health Research and Education; and private donors provided financial support for direct costs of AZMATICS.

Prior presentation: Presented in part at the North American Primary Care Research Group Conference, Seattle, Washington (November 13-17, 2010); and at the European Respiratory Society Conference, Amsterdam, the Netherlands (September $24-28,2011)$. The following organizations provided in-kind support: the Wisconsin Research and Education Network; the Community-Academic Partnerships core of the University of cient evidence to support or refute the use of macrolides in patients with chronic asthma and recommended further studies. ${ }^{1}$ Potential macrolide mechanisms of action include nonantimicrobial effects, ${ }^{2}$ antimicrobial activity targeting the respiratory pathogens Chlamydia pneumoniae and Mycoplasma pneumoniae, or both. ${ }^{3}$

Wisconsin Institute for Clinical and Translational Research, funded through a National Institutes of Health Clinical and Translational Science Award, grant no. 1 UL1 RR025011; the Wisconsin Network for Health Research; the University of Wisconsin Department of Biostatistics; and the Center for Urban Population Health, Milwaukee, WI.

Conflict of interest: none declared.

Disclaimer: The funding sources had no involvement in study design, data collection, analysis, interpretation, report writing or publication. The writing committee had sole control and access to all data and accepts full responsibility for the content of this report.

Corresponding author: Dr. David L. Hahn, Dean East Clinic, 1821 S. Stoughton Road, Madison, WI 53716 (E-mail: dlhahn@wisc.edu). 
Current guideline-recommended asthma treatments have limited generalizability because of a lack of effectiveness trials of representative samples of asthma patients and because of the systematic exclusion of large numbers of asthma patients from the efficacy trials on which the guidelines are based. On average, 19 of 20 people with physician-diagnosed asthma were excluded from the clinical research $^{4,5}$ and more than half of adults with asthma may remain poorly controlled, even when they are treated. ${ }^{6}$ Thus, it is important to test therapies for asthma in generalizable effectiveness trials.

We therefore conducted a primary care, practice-based effectiveness trial designed to include 3 months of adjunctive treatment (in addition to usual care) with the azalide macrolide azithromycin followed by a 9-month observational period after treatment. The goal of our trial, AZithroMycinAsthma Trial In Community Settings (AZMATICS), was to investigate whether azithromycin has value for patients with persistent asthma in reducing the severity of their symptoms over time.

\section{Methods}

Adults with persistent asthma symptoms as defined by current guidelines ${ }^{7}$ were randomized to receive 12 weekly doses of azithromycin or placebo as adjunctive therapy between June 2006 and November 2009. Self-reported questionnaire data were collected for 1 year after randomization. Patients were recruited and enrolled from community practice-

Table 1. Inclusion, Exclusion, and Outcome Criteria

Criteria

Inclusions $\quad$ Adults $\geq 18$ years of age with physician-diagnosed asthma (symptomatic $\geq 2$ days per week and/or $\geq 2$ nights per month or in exacerbation)

- Objective evidence for reversible airway obstruction ( $\geq 12 \%$ and $\geq 200 \mathrm{~mL}$ change in $\mathrm{FEV}_{1}{ }^{8}$ and/or a $25 \%$ and $60 \mathrm{~L} / \mathrm{min}$ change in $\mathrm{PEFR}^{9}$ ) either spontaneously or after treatment

- Asthma for at least 6 months before enrollment

Exclusions $\quad$ Not English literate or has no email address or Internet access

- Macrolide allergy

- Pregnant or lactating

- $\geq 4$ weeks of continuous use of macrolides, tetracyclines, or quinolones within 6 months of randomization

- Asthma symptoms less than 6 months' duration

- Unstable asthma requiring immediate emergency care

- Comorbidities likely to interfere with study assessments or follow-up (eg, cystic fibrosis, obstructive sleep apnea requiring CPAP, cardiomyopathy, congestive heart failure, terminal cancer, alcohol or other drug abuse, or any other serious medical condition that, in the opinion of the study physician, would seriously interfere with or preclude assessment of study outcomes or completion of study assessments)

- Medical conditions for which macrolide administration may possibly be hazardous (eg, acute or chronic hepatitis, cirrhosis, or other liver disease; chronic kidney disease; or history of prolonged cardiac repolarization and QT interval or torsades de pointes).

- Specified medications for which close monitoring has been recommended in the setting of macrolide administration (digoxin, theophylline, warfarin, ergotamine or dihydroergotamine, triazolam, carbamazepine, cyclosporine, hexobarbital, or phenytoin)

Outcomes $\quad$ Asthma symptom scores $(0=$ none, $1=$ mild, $2=$ moderate, $3=$ severe, $4=$ worst ever $)$ within the past 24 hours; every 1.5 months

- AQL (Juniper AQL questionnaire) ${ }^{10}$ within the past 2 weeks; every 3 months

- Asthma control (mini-Juniper Asthma Control Questionnaire, without pulmonary function) ${ }^{11,12}$ within the past week; every 3 months

- Exacerbations (a steroid burst, an unscheduled or emergency visit and/or a hospitalizations for asthma) within the past 1.5 months; every 1.5 months

- Other respiratory illnesses within the past 1.5 months; every 1.5 months

- Off-study antibiotic use within the past 1.5 months; every 1.5 months

- Adverse events within the past 1.5 months; every 1.5 months

- Use of asthma-controller medications (oral or inhaled steroids, LABAs, or antileukotriene agents) within the past 3 months; every 3 months

- Self-reported improvement in asthma (compared with baseline) within the past 3 months; every 3 months

AQL, asthma quality of life; CPAP, continuous positive airway pressure; $\mathrm{FEV}_{1}$, forced expiratory volume in 1 second; LABA, long-acting bronchodilators; PEFR, peak expiratory flow rate. 
based settings throughout North America. Study clinician members and/or staff of 5 practice-based research networks (PBRNs) and one communitybased allergist enrolled patients from their practices for this study. The PBRNs included one nationwide network (American Academy of Family Physicians National Research Network) and 4 regional networks (Ambulatory Network for Scholarship and Research, Illinois; Cleveland Ambulatory Research Network, Ohio; Oklahoma Physicians Resource/Research Network; and the Wisconsin Research and Education Network). Further participant details are provided in the Acknowledgments. During this "real-world" study, we encountered eligible patients, most of whom had severe treatment-resistant or refractory asthma, who declined randomization in favor of being treated with azithromycin. Rather than exclude these patients entirely, we elected to enroll them as a parallel observational cohort. Patients who opted to participate in this "open-label" (OL) arm received a prescription for azithromycin from their personal physician and were followed for the same outcomes as the randomized arm.

\section{Study Eligibility}

Eligibility criteria can be found in Table 1. Community-based clinicians enrolled and randomized eligible patients and remained available to assess side effects or severe adverse reactions, but they were not involved in follow-up data collection. All subjects continued to receive usual asthma care from their doctor. All study sites received approval

Figure 1. CONSORT diagram. *Unavailable pulmonary function tests (PFTs) as the only disqualification of 67 of 170. ${ }^{\dagger}$ Nonqualifying PFTs in 10 of 24.

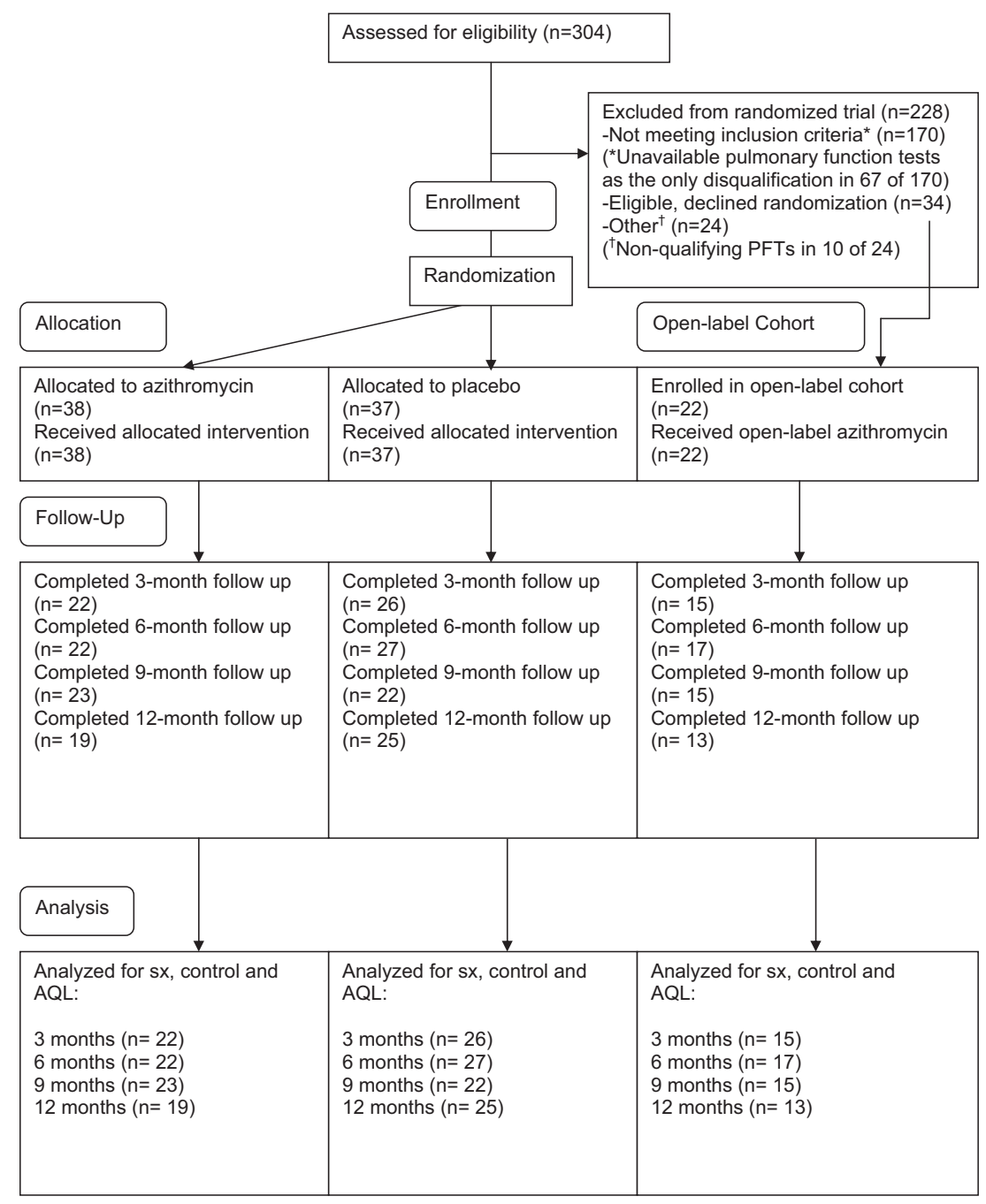


from their respective human subject committees, and subjects provided written, informed consent.

\section{Randomization and Masking}

An independent statistician prepared the randomization codes used for subject assignment to the azithromycin or placebo study arms. The investigators, study subjects, and study site personnel were blinded to treatment allocation. Study medication was azithromycin $600 \mathrm{mg}, 1$ tablet daily for 3 days followed by 1 tablet weekly for 11 weeks, or identical matching placebo tablets. Each study site

Table 2. Patient Characteristics

\begin{tabular}{|c|c|c|c|c|}
\hline Characteristic & $\begin{array}{c}\text { Randomized } \\
\text { Placebo }(n=37)\end{array}$ & $\begin{array}{c}\text { Randomized } \\
\text { Azithromycin }(\mathrm{n}=38)\end{array}$ & $\begin{array}{l}\text { Open-Label } \\
\text { Azithromycin }(n=22)\end{array}$ & $P^{\star}$ \\
\hline Age(years), mean(SD) & $47.4(14.2)$ & $45.7(15.5)$ & $45.4(15.2)$ & $.621 / .745$ \\
\hline At asthma diagnosis & $24(<1-59)$ & $24(<1-58)$ & $28(11-59)$ & $.603 / .104$ \\
\hline Diagnosis at age $\geq 18$ years & $21(57)$ & $24(63)$ & $19(86)$ & $.641 / .023$ \\
\hline Male sex & $13(35)$ & $11(29)$ & $12(55)$ & $.626 / .078$ \\
\hline Smoking status & & & & $.187 / .028$ \\
\hline Never & $13(35)$ & $20(53)$ & $16(73)$ & \\
\hline Former & $19(51)$ & $12(32)$ & $6(27)$ & \\
\hline Current & $5(14)$ & $6(16)$ & $0(0)$ & \\
\hline White race & $33(89)$ & $36(95)$ & $18(82)$ & $.430 / .227$ \\
\hline Education, median years (range) & $15(10-20)$ & $14(12-22)$ & $17(12-25)$ & $.550 /<.001$ \\
\hline$\geq$ High school graduate & $35(95)$ & $38(100)$ & $21(100)$ & $.240 / 1.000$ \\
\hline Chronic sinusitis & $11(30)$ & $14(37)$ & $17(77)$ & $.626 /<.001$ \\
\hline \multicolumn{5}{|l|}{ Atopy } \\
\hline Allergy tested & $18(53)$ & $18(49)$ & $19(86)$ & $.814 / .003$ \\
\hline Negative & $2(11)$ & $1(6)$ & $6(32)$ & $.759 / .003$ \\
\hline Positive for $1-3$ positive & $4(22)$ & $3(17)$ & $8(42)$ & \\
\hline Positive for $\geq 4$ & $12(67)$ & $14(78)$ & $5(26)$ & \\
\hline Infectious asthma $^{+}$ & $6(16)$ & $17(46)$ & $13(59)$ & $.011 / .024$ \\
\hline Exacerbations (previous 2 years), n (\%) & $24(65)$ & $26(68)$ & $14(64)$ & $.809 / .802$ \\
\hline Hospitalized & $0(0)$ & $2(5)$ & $4(18)$ & $.493 / .023$ \\
\hline Emergency visit & $14(38)$ & $19(50)$ & $9(41)$ & $.355 / 1.000$ \\
\hline Steroid burst & $22(59)$ & $24(63)$ & $13(59)$ & $.815 / 1.000$ \\
\hline \multicolumn{5}{|l|}{ Baseline asthma severity, n (\%) } \\
\hline Day symptom frequency ${ }^{\ddagger}$ & & & & $.675 / .009$ \\
\hline Mild to moderate & $35(95)$ & $34(89)$ & $15(68)$ & \\
\hline Severe & $2(5)$ & $4(11)$ & $7(32)$ & \\
\hline Night symptom frequency ${ }^{\ddagger}$ & & & & $1.000 / .046$ \\
\hline Mild to moderate & $33(89)$ & $33(87)$ & $15(68)$ & \\
\hline Severe & $4(11)$ & $5(13)$ & $7(32)$ & \\
\hline Coexisting COPD & $8(22)$ & $5(13)$ & $2(9)$ & $.375 / .509$ \\
\hline \multicolumn{5}{|l|}{ Lung function, mean (SD) } \\
\hline $\mathrm{FEV}_{1}, \mathrm{~L}(\mathrm{n})$ & 18 & 19 & 7 & \\
\hline Low $^{\S}$ & $2.24(1.25)$ & $2.33(1.05)$ & $2.48(1.19)$ & $.812 / .688$ \\
\hline \% Changel & $42(47.4)$ & $26(25.9)$ & $33(26.8)$ & $.214 / .969$ \\
\hline PEFR, L/min (n with value) & 25 & 25 & 18 & \\
\hline Low $\$$ & $258(110)$ & $276(110)$ & $300(105)$ & $.566 / .281$ \\
\hline \% Change"l & $62(56)$ & $63(49)$ & $85(63)$ & $.927 / .140$ \\
\hline Any controller medication & $33(89)$ & $25(66)$ & $19(86)$ & $.026 / .549$ \\
\hline Inhaled corticosteroid & $30(81)$ & $24(63)$ & $18(82)$ & \\
\hline Long-acting bronchodilator ${ }^{\mathbb{I I}}$ & $26(70)$ & $14(37)$ & $15(68)$ & \\
\hline Leukotriene inhibitor & $8(22)$ & $9(24)$ & $6(27)$ & \\
\hline Oral prednisone & $4(11)$ & $2(5)$ & $1(5)$ & \\
\hline
\end{tabular}


Table 2. Continued

\begin{tabular}{lcccc}
\hline Characteristic & $\begin{array}{c}\text { Randomized } \\
\text { Placebo }(\mathrm{n}=37)\end{array}$ & $\begin{array}{c}\text { Randomized } \\
\text { Azithromycin }(\mathrm{n}=38)\end{array}$ & $\begin{array}{c}\text { Open-Label } \\
\text { Azithromycin }(\mathrm{n}=22)\end{array}$ & $P^{*}$ \\
\hline Baseline asthma measures, mean (SD)** & & & & \\
$\quad$ Overall asthma symptoms & $1.48(0.94)$ & $1.42(0.77)$ & $2.06(0.73)$ & $.744 / .005$ \\
Asthma quality of life & $4.97(1.28)$ & $4.98(1.27)$ & $4.12(1.29)$ & $.988 / .023$ \\
Asthma control & $1.56(1.02)$ & $1.75(0.93)$ & $2.26(1.35)$ & $.424 / .090$ \\
\hline
\end{tabular}

Values provided as $\mathrm{n}(\%)$ unless otherwise indicated.

${ }^{*} P$ values comparing randomized placebo versus randomized azithromycin/randomized cohort versus open-label cohort.

${ }^{\dagger}$ History showed first asthma symptoms began after an acute respiratory illness.

${ }^{\ddagger}$ Day: mild $=\geq 2$ days/week to less than daily; moderate $=\geq 1$ per day to less than continuous; severe $=$ continuous. Night: mild $=$ $\geq 2$ per month to $\leq 1$ per week; moderate $=>1$ per week to $\leq 1$ per night; severe $=>1$ per night.

${ }^{\S}$ Before bronchodilator use or lowest spontaneous value.

"Based on data after bronchodilator use or highest spontaneous value. Some subjects had either FEV $_{1}$ or PEFR values, not both.

IIAll subjects using a long-acting bronchodilator also were using an inhaled corticosteroid.

${ }^{* *}$ See Methods for definitions.

$\mathrm{COPD}$, chronic obstructive pulmonary disease; $\mathrm{FEV}_{1}$, forced expiratory volume in 1 second; PEFR, peak expiratory flow rate.

received coded study medication bottles (1:1 allocation) in blocks of 6 and was instructed to distribute them (numbered 1 to 6 ) in numerical ascending order to eligible consenting study subjects. After 3 weeks of taking study medication, subjects were asked to guess their allocation.

\section{open-Label Treatment}

Internet trial registration (http://clinicaltrials.gov/ show/NCT00266851) and another Internet site (http://asthmastory.com) identified asthma patients wanting to participate in AZMATICS. ${ }^{13}$ When they learned that they had a $50 \%$ chance of receiving a placebo, many of these patients declined to be randomized but remained interested in the use of azithromycin for treatment of their asthma. Institutional review board approval was obtained to enter eligible subjects requesting azithromycin into a parallel, OL observational cohort. OL subjects obtained a 12-week prescription for weekly azithromycin from their personal physician and were monitored for the same baseline and outcome data that were being collected for the randomized cohort. Because 600-mg azithromycin tablets were not uniformly available, OL treatment consisted of 2 azithromycin tablets (250 $\mathrm{mg}$ each), to achieve a 500-mg daily dose for 3 days, followed by 3 tablets to achieve a $750-\mathrm{mg}$, once-weekly dose for 11 additional weeks.

\section{Study Outcomes}

Subjects submitted follow-up data via Internet questionnaires. During the first 3 months after ran- domization (the study medication administration period), subjects reported weekly via the Internet whether they had taken their assigned study medication during the previous week. In addition to study medication adherence, subjects also reported weekly on side effects for the first 3 months. Outcome data were recorded every 1.5 months (6 weeks) through 12 months. Outcome measures are listed in Table 1.

\section{Statistical Analysis}

All analyses were by intention to treat, and no subjects with available data were excluded from any analysis. Repeated-measures (RM) analysis of variance (ANOVA) - with intervention and time as fixed effects; subjects as random effects; and age, sex, and ever-smoking as covariates-was conducted for each of the continuous variables. After finding significant effects in the RM ANOVA models, we explored the effects with tests at specific time points. We used Fisher exact test for categorical variables, Wilcoxon rank sum tests for continuous variables (reported as median and range), and $t$ tests for continuous variables (reported as mean and standard deviation). We controlled for the effects of age, sex, ever-smoking, and asthma controller medication using ANOVA for normally distributed continuous outcomes and logistic regression for binary outcomes. On the basis of our pilot results, a total sample size of 58 had $80 \%$ power (for $\alpha=0.05$ ) to detect a 0.66 -unit (13\%) difference in overall asthma symptoms (the primary outcome). AZMATICS used a Data Safety Monitoring 
Board that met approximately every 6 months. The Data Safety Monitoring Board did not identify any reason for early termination.

\section{Results}

\section{Screening and Enrollment}

Of 304 adult asthma patients screened, 97 (32\%) were enrolled ( 38 were randomized to azithromycin, 37 were randomized to placebo, and 22 elected OL treatment). An additional 67 of 304 screened patients $(22 \%)$ who were otherwise eligible lacked pulmonary function data and could not complete the screening process (Figure 1).

\section{Adberence}

Self-reported mean adherence to taking azithromycin or placebo ranged from $96 \%$ to $99 \%$, with no significant differences among the 3 study groups $(P=.706)$. Adherence to reporting follow-up data ranged from 63 of 97 participants $(65 \%)$ at 12 weeks to 57 participants (59\%) at 48 weeks, with no

Figure 2. Differences from baseline for asthma symptoms, quality of life, and control. A: Symptoms—rating of overall asthma symptoms for the past 24 hours (negative numbers indicate decreased symptoms and hence improvement). B: Quality of lifeJuniper Asthma Quality of Life Questionnaire (AQLQ); positive numbers indicate higher quality of life scores and hence improvement). C: Control—Juniper Mini-Asthma Control Questionnaire (ACQ; negative numbers indicate better control and hence improvement). See Methods for details. Symbols represent the mean paired differences from baseline. Bars represent 95\% confidence intervals. $* P<0.05, * * P<0.01, * * * P<0.001$ ( $t$ tests, placebo versus open label).
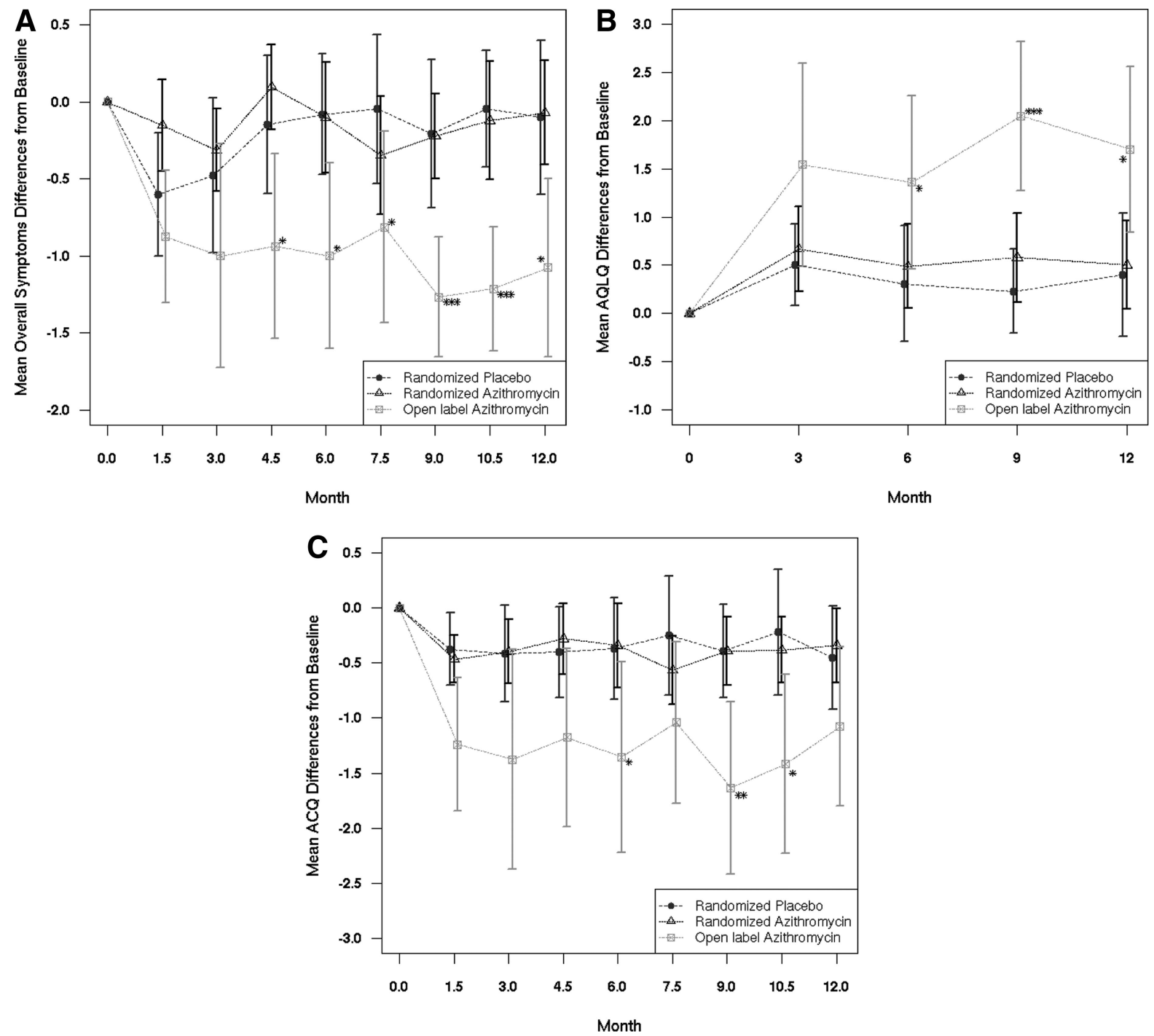


\begin{tabular}{|c|c|c|c|c|c|}
\hline & $\begin{array}{l}\text { Randomized } \\
\text { Placebo }\end{array}$ & $\begin{array}{l}\text { Randomized } \\
\text { Azithromycin }\end{array}$ & $\begin{array}{l}\text { Open-label } \\
\text { Azithromycin }\end{array}$ & $\begin{array}{l}P \text {, Placebo vs } \\
\text { Randomized } \\
\text { Azithromycin }\end{array}$ & $\begin{array}{l}P \text {, Placebo vs } \\
\text { Open-Label }\end{array}$ \\
\hline \multicolumn{6}{|c|}{$\begin{array}{l}\text { Change in overall asthma } \\
\text { symptoms, from } \\
\text { baseline }\end{array}$} \\
\hline Week 6 & $-0.60(1.07)(\mathrm{n}=30)$ & $-0.15(0.83)(n=33)$ & $-0.88(0.81)(\mathrm{n}=16)$ & $.071 / .071^{\dagger}$ & $.333 / .428^{\dagger}$ \\
\hline Week 12 & $-0.48(1.16)(n=23)$ & $-0.31((0.74)(\mathrm{n}=32)$ & $-1.0(1.37)(\mathrm{n}=16)$ & $.551 / .580^{\dagger}$ & $.223 / .723^{+}$ \\
\hline Week 18 & $-0.15(1.13)(\mathrm{n}=27)$ & $0.10(0.75)(\mathrm{n}=31)$ & $-0.94(1.12)(\mathrm{n}=16)$ & $.344 / .178^{\dagger}$ & $.034 / .161^{\dagger}$ \\
\hline Week 24 & $-0.08(0.95)(\mathrm{n}=25)$ & $-0.10(0.96)(n=30)$ & $-1.0(1.17)(\mathrm{n}=17)$ & $.939 / .599^{\dagger}$ & $.012 / .013^{+}$ \\
\hline Week 30 & $-0.05(1.09)(\mathrm{n}=22)$ & $-0.34(1.01)(n=29)$ & $-0.81(1.17)(\mathrm{n}=16)$ & $.322 / .280^{\dagger}$ & $.048 / .870^{\dagger}$ \\
\hline Week 36 & $-0.21(1.14)(\mathrm{n}=24)$ & $-0.22(0.70)(\mathrm{n}=27)$ & $-1.27(0.70)(\mathrm{n}=15)$ & $.959 / .942^{\dagger}$ & $.001 / .017^{\dagger}$ \\
\hline Week 42 & $-0.04(0.88)(n=23)$ & $-0.12(0.93)(n=25)$ & $-1.21(0.70)(n=14)$ & $.770 / .858^{\dagger}$ & $<.001 / .001^{\dagger}$ \\
\hline Week 48 & $-0.10(1.07)(\mathrm{n}=20)$ & $-0.07(0.88)(n=29)$ & $-1.07(0.95)(\mathrm{n}=13)$ & $.916 / .758^{\dagger}$ & $.011 / .067^{\dagger}$ \\
\hline \multicolumn{6}{|c|}{$\begin{array}{l}\text { Change in AQL, from } \\
\text { baseline }\end{array}$} \\
\hline Week 12 & $0.50(0.95)(\mathrm{n}=22)$ & $0.67(1.10)(\mathrm{n}=26)$ & $1.54(1.91)(\mathrm{n}=15)$ & $.584 / .682^{\dagger}$ & $.067 / .180^{\dagger}$ \\
\hline Week 24 & $0.31(1.36)(n=22)$ & $0.49(1.11)(\mathrm{n}=27)$ & $1.36(1.75)(\mathrm{n}=17)$ & $.618 / .382^{\dagger}$ & $.049 / .151^{\dagger}$ \\
\hline Week 36 & $0.23(1.02)(\mathrm{n}=23)$ & $0.58(1.04)(n=22)$ & $2.05(1.40)(\mathrm{n}=15)$ & $.261 / .342^{\dagger}$ & $<.001 / .001^{\dagger}$ \\
\hline Week 48 & $0.40(1.33)(\mathrm{n}=19)$ & $0.50(1.10)(\mathrm{n}=25)$ & $1.70(1.42)(\mathrm{n}=13)$ & $.784 / .929^{\dagger}$ & $.015 / .068^{\dagger}$ \\
\hline \multicolumn{6}{|c|}{$\begin{array}{l}\text { Change in asthma } \\
\text { control, from } \\
\text { baseline }\end{array}$} \\
\hline Week 6 & $-0.37(0.88)(\mathrm{n}=30)$ & $-0.46(0.60)(\mathrm{n}=33)$ & $-1.24(1.14)(\mathrm{n}=16)$ & $.634 / .654^{\dagger}$ & $.014 / .009^{\dagger}$ \\
\hline Week 12 & $-0.41(1.01)(\mathrm{n}=23)$ & $-0.40(0.80)(n=32)$ & $-1.38(1.87)(n=16)$ & $.946 / .998^{\dagger}$ & $.075 / .324^{\dagger}$ \\
\hline Week 18 & $-0.40(1.05)(\mathrm{n}=27)$ & $-0.28(0.88)(\mathrm{n}=31)$ & $-1.18(1.53)(\mathrm{n}=16)$ & $.637 / .573^{\dagger}$ & $.085 / .179^{\dagger}$ \\
\hline Week 24 & $-0.37(1.12)(\mathrm{n}=25)$ & $-0.34(1.03)(\mathrm{n}=30)$ & $-1.35(1.69)(\mathrm{n}=17)$ & $.925 / .536^{\dagger}$ & $.045 / .034^{\dagger}$ \\
\hline Week 30 & $-0.25(1.22)(\mathrm{n}=22)$ & $-0.56(0.81)(\mathrm{n}=29)$ & $-1.04(1.38)(n=16)$ & $.307 / .281^{\dagger}$ & $.078 / .163^{\dagger}$ \\
\hline Week 36 & $-0.39(1.00)(\mathrm{n}=24)$ & $-0.39(0.79)(\mathrm{n}=27)$ & $-1.63(1.41)(\mathrm{n}=15)$ & $1.000 / .852^{\dagger}$ & $.007 / .015^{\dagger}$ \\
\hline Week 42 & $-0.22(1.32)(\mathrm{n}=23)$ & $-0.38(0.72)(\mathrm{n}=25)$ & $-1.42(1.41)(n=14)$ & $.604 / .817^{\dagger}$ & $.016 / .068^{\dagger}$ \\
\hline Week 48 & $-0.45(1.00)(\mathrm{n}=20)$ & $-0.34(0.88)(n=29)$ & $-1.08(1.20)(\mathrm{n}=13)$ & $.692 / .525^{\dagger}$ & $.132 / .379^{\dagger}$ \\
\hline \multicolumn{6}{|c|}{$\begin{array}{l}\text { AQL improved } \geq 1 \text { unit, } \\
\mathrm{n} / \mathrm{N}(\%)\end{array}$} \\
\hline Week 12 & $5 / 22(23)$ & $11 / 26(42)$ & $9 / 15(60)$ & $.221 / .136^{\ddagger}$ & $.038 / .098^{\ddagger}$ \\
\hline Week 24 & $6 / 22(27)$ & $8 / 27(30)$ & $11 / 17(65)$ & $1.000 / .745^{\ddagger}$ & $.026 / .048^{\ddagger}$ \\
\hline Week 36 & $5 / 23(22)$ & $6 / 22(27)$ & $12 / 15(80)$ & $.738 / .738^{\ddagger}$ & $.001 / .003^{\ddagger}$ \\
\hline Week 48 & 4/19 (21) & $9 / 25(36)$ & $7 / 13(54)$ & $.335 / .386^{\ddagger}$ & $.072 / .116^{\ddagger}$ \\
\hline \multicolumn{6}{|c|}{$\begin{array}{l}\text { Asthma control improved } \\
\quad \geq 1 \text { unit, } \mathrm{n} / \mathrm{N}(\%)\end{array}$} \\
\hline Week 6 & $6 / 30(20)$ & 4/33 (12) & $9 / 16(56)$ & $.498 / .421^{\ddagger}$ & $.021 / .010^{\ddagger}$ \\
\hline Week 12 & $7 / 23(30)$ & $7 / 32(22)$ & $11 / 16(69)$ & $.539 / .531^{\ddagger}$ & $.025 / .045^{\ddagger}$ \\
\hline Week 18 & $7 / 27(26)$ & 4/31 (13) & $9 / 16(56)$ & $.315 / .437^{\ddagger}$ & $.059 / .054^{\ddagger}$ \\
\hline Week 24 & $6 / 25(24)$ & $10 / 30(33)$ & $10 / 17(59)$ & $.556 / .144^{\ddagger}$ & $.029 / .017^{\ddagger}$ \\
\hline Week 30 & $5 / 22(23)$ & $9 / 29(31)$ & $8 / 16(50)$ & $.546 / .502^{\ddagger}$ & $.098 / .105^{\ddagger}$ \\
\hline Week 36 & $5 / 24(21)$ & $6 / 27(22)$ & $10 / 15(67)$ & $1.000 / .875^{\ddagger}$ & $.007 / .009^{\ddagger}$ \\
\hline Week 42 & $6 / 23(26)$ & $7 / 25(28)$ & $8 / 14(57)$ & $1.000 / .862^{\ddagger}$ & $.085 / .152^{\ddagger}$ \\
\hline Week 48 & $5 / 20(25)$ & $8 / 29(28)$ & $5 / 13(38)$ & $1.000 / .980^{\ddagger}$ & $.461 / .998^{\ddagger}$ \\
\hline
\end{tabular}

All values are mean $(\mathrm{SD})$ unless otherwise indicated.

*See Methods for definitions.

${ }^{\dagger}$ Univariate ( $t$ test)/multivariate (analysis of variance); controlled for age, sex, and ever-smoking at each time point, as well as for controller medication use at weeks $12,24,36$, and 48 (controller data is unavailable for other time points).

${ }^{\ddagger}$ Univariate (Fisher exact test)/multivariate (logistic regression); controlled for age, sex, and ever-smoking at each time point, as well as for controller medication use at weeks $12,24,36$, and 48 (controller data is unavailable for other time points).

AQL, asthma quality of life. 
significant differences between study groups $(P=$ $.122)$.

\section{Baseline Characteristics}

Table 2 presents the patient characteristics. The study group was mostly white and non-Hispanic with a high school education or greater and a broad range of age at asthma onset. The randomized groups were well balanced in major baseline characteristics (age, sex, smoking status, education, and asthma severity), but the group randomized to azithromycin reported more asthma onset after an acute respiratory illness ("infectious asthma") and less use of controller medication compared with the placebo group. Compared with the randomized groups, the OL cohort had significantly greater asthma severity at baseline (more hospitalizations for asthma, greater day and night symptom frequency, worse overall asthma symptoms, and worse asthma quality of life [AQL]); more adult-onset asthma; more chronic sinusitis; more allergy testing (but fewer positive tests); and more infectious asthma. Of the baseline covariates in RM ANOVAs, smoking was significantly associated with worse symptoms, AQL, and asthma control $(P<.05$ for each); older age was significantly associated only with worse AQL $(P<.05)$, and sex was not significant in any analysis.

\section{Outcomes}

\section{Randomized Trial}

After 3 weeks of receiving study medication, 13\% of those randomized to placebo and 29\% randomized to azithromycin correctly guessed their allocation; $34 \%$ of placebo and $29 \%$ of azithromycin subjects guessed incorrectly, and the remainder were unsure of their allocation $(P=.27)$. Subjects

Figure 3. Improvement in asthma quality of life (AQL) after azithromycin treatment may be "all or none." $\mathrm{AQL}$ change scores from baseline to 12 months after enrollment ( 9 months after treatment completion) are defined as follows: "AQL change $<0$ " = AQL change worse than baseline; "AQL change $0<.5$ " = change between 0 to $<.5$ units; "AQL change $0.5<1$ " = change between 0.5 to $<1$ (change of 0.5 unit is considered the minimum clinically important change); "AQL change $1<2$ " = change between 1 and 2 (change $>1.5$ units represents a large change); "AQL change $\geq 2$ " = change of 2 units or more. The contrasting patterns between placebo and open-label azithromycin were statistically significant, as noted in the text. The differences between randomized azithromycin and placebo were not statistically significant, as noted in the text.

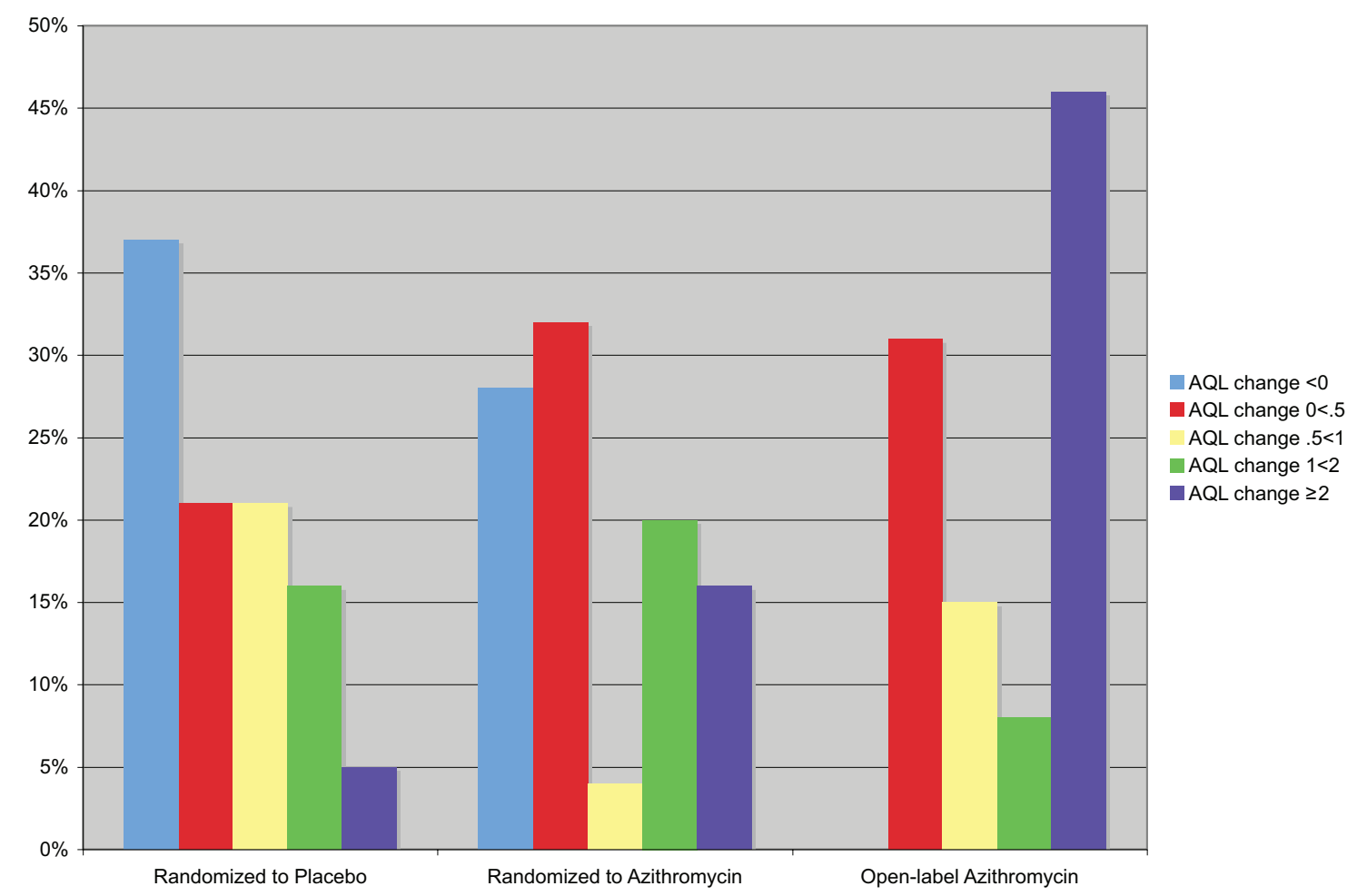


randomized to azithromycin or placebo had no significant differences in overall asthma symptoms, AQL, or asthma control (Figure 2 and Table 3). At 1 year, subjects randomized to azithromycin were more likely than placebo subjects to have an AQL score $\geq 1$-unit increase compared with baseline (36\% vs $21 \%$ ). This difference was not statistically significant $(P=.335)$. Compared with subjects randomized by PBRN members $(\mathrm{n}=69)$, subjects randomized by the community allergist $(\mathrm{n}=6)$ were more likely to have been skin tested (49\% of PBRN subjects skin tested vs $100 \%$ of allergist subjects; $P=$ .024) but otherwise were similar in baseline characteristics, including comparable distribution of skin test results. Removing the allergist-recruited subjects from the RM ANOVA did not alter the outcome results (data not shown).

\section{Open-Label Cohort}

Comparing the OL and placebo groups, RM ANOVA found that the effect of intervention and the interaction of intervention and time were significant for symptoms, AQL, and asthma control $(P<.05$ for each). In univariate analyses, OL group asthma symptoms were significantly improved from month 4.5 to month 12 compared with placebo and AQL was significantly improved from month 6 to month 12, whereas asthma control

Table 4. Side Effects*

\begin{tabular}{|c|c|c|c|c|}
\hline Side Effects, n (\%) & Randomized Placebo & Randomized Azithromycin & Open-Label Azithromycin & $P^{\dagger}$ \\
\hline Nausea & & & & $.016 / .008 / .458$ \\
\hline None & $31(91)$ & $25(71)$ & $12(60)$ & \\
\hline Mild to moderate & $1(3)$ & $9(26)$ & $6(30)$ & \\
\hline Severe & $2(6)$ & $1(3)$ & $2(10)$ & \\
\hline Vomiting & & & & $1.000 / .128 / .456$ \\
\hline None & $32(94)$ & $33(94)$ & $18(90)$ & \\
\hline Mild to moderate & $0(0)$ & $1(3)$ & $2(10)$ & \\
\hline Severe & $2(6)$ & $1(3)$ & $0(0)$ & \\
\hline Stomach pain & & & & $.076 / .001 / .196$ \\
\hline None & $30(88)$ & $24(69)$ & $9(45)$ & \\
\hline Mild to moderate & $3(9)$ & $10(29)$ & $10(50)$ & \\
\hline Severe & $1(3)$ & $1(3)$ & $1(5)$ & \\
\hline Diarrhea & & & & $.106 / .002 / .196$ \\
\hline None & $29(85)$ & $23(66)$ & $9(45)$ & \\
\hline Mild to moderate & $3(9)$ & $10(29)$ & $10(50)$ & \\
\hline Severe & $2(6)$ & $2(6)$ & $1(5)$ & \\
\hline Rash & & & & $.743 / .046 / .420$ \\
\hline None & $33(97)$ & $33(94)$ & $16(80)$ & \\
\hline Mild to moderate & $0(0)$ & $2(6)$ & $3(15)$ & \\
\hline Severe & $1(3)$ & $1(3)$ & $1(5)$ & \\
\hline Swelling & & & & $.239 / .716 / .128$ \\
\hline None & $32(94)$ & $35(100)$ & $18(90)$ & \\
\hline Mild to moderate & $1(3)$ & $0(0)$ & $2(10)$ & \\
\hline Severe & $1(3)$ & $0(0)$ & $0(0)$ & \\
\hline Hearing loss & & & & $.743 / 1.000 / .999$ \\
\hline None & $32(94)$ & $34(97)$ & $19(95)$ & \\
\hline Mild to moderate & $1(3)$ & $1(3)$ & $1(5)$ & \\
\hline Severe & $1(3)$ & $0(0)$ & $0(0)$ & \\
\hline Vaginal candidiasis & & & & $.670 / 1.000 / .999$ \\
\hline None & $20(91)$ & $21(84)$ & $7(88)$ & \\
\hline Mild to moderate & $3(9)$ & $4(16)$ & $1(13)$ & \\
\hline Severe & $0(0)$ & $0(0)$ & $0(0)$ & \\
\hline
\end{tabular}

*Worst reported severity during the 12 -week treatment period.

${ }^{\dagger}$ Fisher exact tests: randomized placebo versus randomized azithromycin/randomized placebo versus open-label azithromycin/ randomized azithromycin versus open-label azithromycin. 


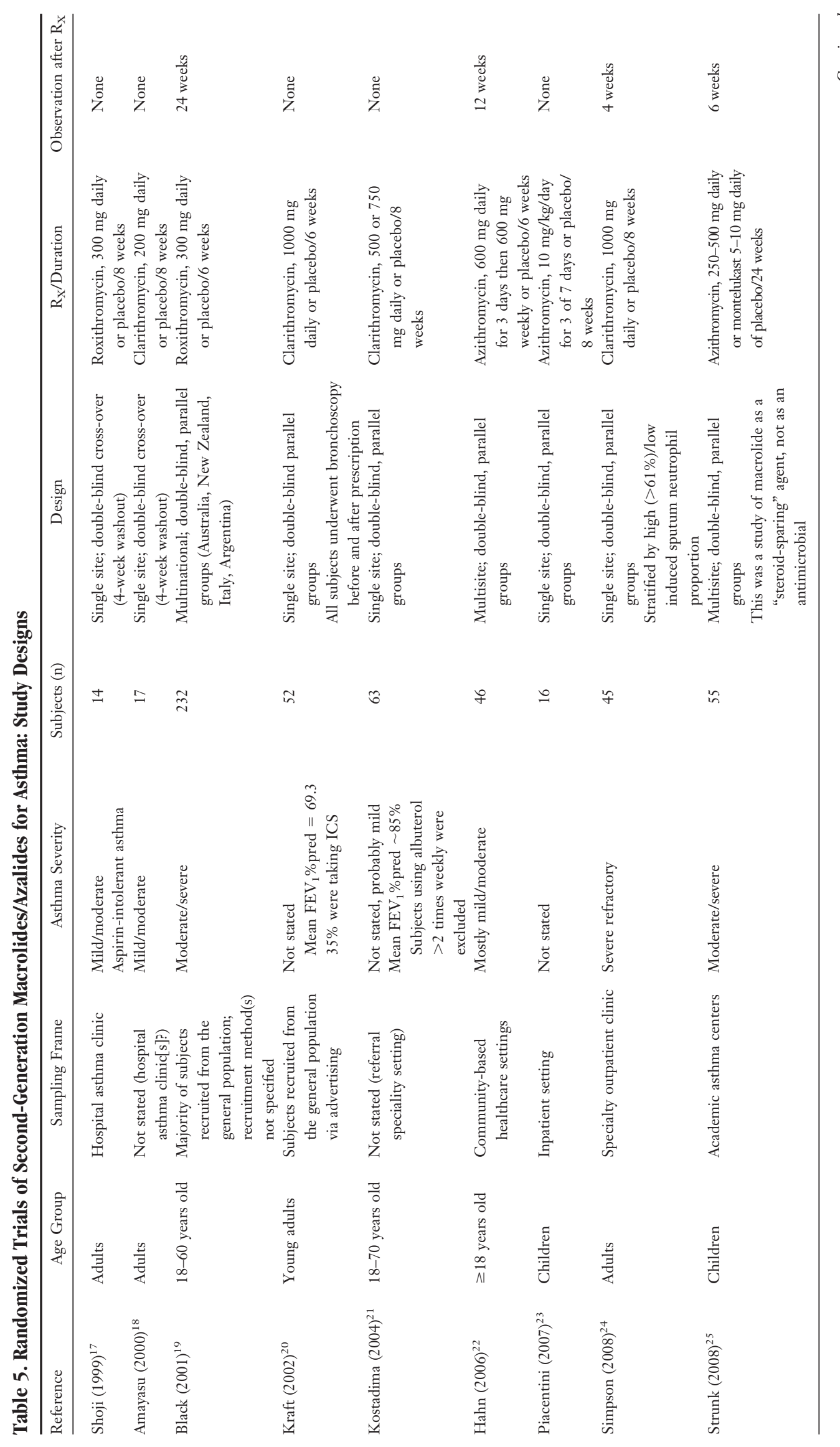


improvements were less consistent (Figure 2). In multivariate analyses (controlled for age, sex, eversmoking, and concurrent controller medication use) the OL group reported significant improvements in symptoms, AQL, and asthma control that were maximal at study month 9 and waned somewhat at month 12 (Table 3).

AQL score change of 1 unit or more was a prespecified secondary outcome. AQL $\geq 1$-unit improvement was achieved significantly more often in OL than in placebo subjects at the 3-, 6-, and 9-month time points. A similar but less consistent pattern was noted for asthma control scores with a $\geq 1$-unit improvement (Table 3). After adjustment for age, sex, ever-smoking, and asthma controller medication use at 9 months $(6$ months after treatment completion), $80 \%$ of OL patients versus $22 \%$ of those enrolled in the placebo arm reported AQL score changes of $\geq 1$-unit improvement ( $P=.001$; number needed to treat $[\mathrm{NNT}]=2)$ and $67 \%$ versus $21 \%$ reported asthma control score changes of $\geq 1$-unit improvement $(P=.023$; NNT $=3)$. AQL and asthma control score improvements of $\geq 1$ unit also were correlated significantly with selfreported asthma improvement at all time points $(P<.01$ for each).

We performed further exploratory analyses of different increments of change in AQL score up to and including a change of $\geq 2$ units (Figure 3 ). The results showed that changes in AQL after azithromycin (both randomized or OL) assumed U-shaped distributions, whereas changes in $\mathrm{AQL}$ for placebo were skewed to the left, suggesting a binary "all or none" response to azithromycin. Finding patient characteristics that predict a treatment response are potentially important. Other than asthma severity, however, our data yielded no indications that patients' clinical characteristics were predictive of an azithromycin treatment response. For example, we analyzed OL and placebo subjects in a logistic model of AQL change of $\geq 2$ units from baseline as the dependent variable and included age, sex, smoking status, and "infectious asthma" as other possible predictors. In this model, only azithromycin treatment was a significant predictor of $\mathrm{AQL} \geq 2(P=.026)$.

\section{Exacerbations}

This study was not powered to detect significant differences in exacerbation frequency. During the 12 -month study period, $51 \%$ of subjects reported one or more asthma exacerbations. There were no 
significant differences between the 3 study groups in exacerbation frequency at any time point or cumulatively.
Serious Adverse Events and Side Effects

One subject allocated to placebo was hospitalized for acute coronary syndrome. Another subject

Table 6. Randomized Trials of Second-Generation Macrolides/Azalides for Asthma: Exclusions, Outcomes, and Results

\begin{tabular}{|c|c|c|c|}
\hline Reference & Exclusions* & Outcomes Reported & Results of Macrolide Treatment \\
\hline \multirow[t]{5}{*}{ Shoji $(1999)^{17}$} & Smokers & Blood eosinophils and ECP & Decreased eosinophils/ECP \\
\hline & \multirow[t]{4}{*}{ Controller medication } & Sputum cell counts and ECP & Decreased eosinophils/ECP \\
\hline & & & $\begin{array}{l}\text { (No differences in sputum } \\
\text { neutrophils) }\end{array}$ \\
\hline & & Sulpyrine provocation test & Not improved \\
\hline & & & $\begin{array}{l}\text { No patient-oriented outcomes } \\
\text { reported) }\end{array}$ \\
\hline \multirow[t]{5}{*}{ Amayasu $(2000)^{18}$} & Smokers & Blood eosinophils and ECP & Decreased eosinophils/ECP \\
\hline & Aspirin sensitivity & Sputum cell counts and ECP & Decreased eosinophils/ECP \\
\hline & ARI for 6 weeks & $\mathrm{BHR}$ & Improved \\
\hline & \multirow{2}{*}{$\begin{array}{l}\text { Any asthma controller } \\
\text { medication }\end{array}$} & Pulmonary function & Not improved \\
\hline & & Overall asthma symptoms & Improved \\
\hline \multirow[t]{6}{*}{ Black $(2001)^{19}$} & $\mathrm{FEV}_{1}<50 \%$ predicted & Pulmonary function(PEF) & $\begin{array}{l}\text { Improvement at end of prescription } \\
\text { that waned after prescription }\end{array}$ \\
\hline & $\begin{array}{l}\text { C. pneumoniae } \operatorname{IgG}<1: 64 \text { and } \\
\operatorname{IgA}<1: 16\end{array}$ & Pulmonary function $\left(\mathrm{FEV}_{1}\right)$ & Not improved \\
\hline & Smoking $\geq 20$ pack-years & Asthma symptoms & Not improved \\
\hline & Bronchiectasis & $\mathrm{AQL}$ & Not improved \\
\hline & $\begin{array}{l}\text { Prednisone burst in previous } \\
\text { month }\end{array}$ & & \\
\hline & Respiratory illness & & \\
\hline \multirow[t]{4}{*}{ Kraft $(2002)^{20}$} & Smoking $>5$ pack years & $\mathrm{PCR}+$ for Mpn or Cpn & $\begin{array}{l}31 \text { of } 55 \text { were PCR }+ \text { for Mpn and/ } \\
\text { or Cpn }\end{array}$ \\
\hline & Any cigarette within 2 years & Pulmonary function & $\begin{array}{l}\text { Improved } \mathrm{FEV}_{1} \text { in } \mathrm{PCR}+\text { subject } \\
\text { subgroup }\end{array}$ \\
\hline & Any lung comorbidity & Lung inflammation & Decreased inflammatory cytokines \\
\hline & Any LRTi within 3 months & & $\begin{array}{l}\text { (No patient-oriented outcomes } \\
\text { reported) }\end{array}$ \\
\hline \multirow[t]{7}{*}{ Kostadima $(2004)^{21}$} & Asthma diagnosis $<1$ year ago & BHR & Decreased BHR \\
\hline & Not on ICS & Pulmonary function & Not improved \\
\hline & $\begin{array}{l}\text { Rescue inhaler }>2 \text { times } \\
\text { weekly }\end{array}$ & Serum free cortisol & Not affected \\
\hline & Any smoking history & & (No patient-oriented outcomes \\
\hline & Any other medication & & reported) \\
\hline & $\mathrm{FEV}_{1}<50 \%$ predicted & & \\
\hline & $\begin{array}{l}\text { Any ARI or exacerbation } \\
\text { within } 4 \text { weeks before or } \\
\text { during the study }\end{array}$ & & \\
\hline \multirow[t]{4}{*}{ Hahn $(2006)^{22}$} & \multirow[t]{4}{*}{ None } & $\mathrm{AQL}$ & No improvement \\
\hline & & Rescue medication use & No improvement \\
\hline & & Cpn IgG and IgA antibodies & $\begin{array}{l}\text { Baseline IgA predicted worsening } \\
\text { symptoms }\end{array}$ \\
\hline & & Overall asthma symptoms & $\begin{array}{l}\text { Improved at end of prescription } \\
\text { and persisted after prescription }\end{array}$ \\
\hline \multirow[t]{3}{*}{ Piacentini $(2007)^{23}$} & $\begin{array}{l}\text { Oral steroids in the preceding } \\
3 \text { months or during the } \\
\text { study }\end{array}$ & Lung function & No improvement \\
\hline & \multirow{2}{*}{$\begin{array}{l}\text { Signs of airway infection in } \\
\text { the preceding month or } \\
\text { during the study }\end{array}$} & BHR & Improved \\
\hline & & Lung inflammation & $\begin{array}{l}\text { Reduced induced sputum } \\
\text { neutrophils }\end{array}$ \\
\hline
\end{tabular}


Table 6. Continued

\begin{tabular}{|c|c|c|c|}
\hline Reference & Exclusions* & Outcomes Reported & Results of Macrolide Treatment \\
\hline \multirow[t]{7}{*}{ Simpson $(2008)^{24}$} & Current smoking & Sputum inflammatory markers & $\begin{array}{l}\text { Decreased airway IL-8 and } \\
\text { neutrophils }\end{array}$ \\
\hline & $\begin{array}{l}\text { History of smoking, }>5 \text { pack- } \\
\text { years }\end{array}$ & Pulmonary function & No improvement \\
\hline & Antihistamine medication & BHR & No improvement \\
\hline & & Asthma control & No improvement \\
\hline & & Asthma symptoms & $\begin{array}{l}\text { Decreased wheezing after } \\
\text { prescription }\end{array}$ \\
\hline & & $\mathrm{AQL}$ & $\begin{array}{l}\text { Improved }(\mathrm{NNT}=6 \text { for } \geq 0.5 \\
\text { units improvement) }\end{array}$ \\
\hline & & & $\begin{array}{l}\text { It was unclear whether the AQL } \\
\text { was reported at the end of the } \\
\text { prescription or after the } \\
\text { prescription }\end{array}$ \\
\hline \multirow[t]{4}{*}{ Strunk $(2008)^{25}$} & No controller medication & $\begin{array}{l}\text { Time to inadequate control after } \\
\text { steroid step-down }\end{array}$ & $\begin{array}{l}\text { No improvement in asthma control } \\
\text { (futility analysis) }\end{array}$ \\
\hline & $\begin{array}{l}\mathrm{FEV}_{1}<50 \% \text { pred } \\
>3 \text { hospitalizations in past } \\
\quad \text { year }\end{array}$ & & $\begin{array}{l}\text { Recruitment was discontinued early } \\
\text { ( } 292 \text { screened, only } 55 \\
\text { randomized) }\end{array}$ \\
\hline & Sinus surgery in past year & & \\
\hline & Lung comorbidities & & \\
\hline \multirow[t]{6}{*}{ Sutherland $(2010)^{26}$} & Exacerbation within 6 weeks & Asthma control & No differences in asthma control \\
\hline & ARI within 6 weeks & Pulmonary function & No improvement \\
\hline & $\begin{array}{l}>2 \text { exacerbations or ARI prior } \\
\text { to entry }\end{array}$ & Exhaled nitric oxide & No improvement \\
\hline & Smoking & BHR & Improved \\
\hline & $\begin{array}{l}\text { History of smoking, } \geq 10 \\
\text { pack-years }\end{array}$ & Rescue medication use & No improvement \\
\hline & Lung comorbidities & $\mathrm{AQL}$ & No improvement \\
\hline \multirow[t]{2}{*}{$\begin{array}{l}\text { Hahn (2012), current } \\
\text { study }\end{array}$} & None & Overall asthma symptoms & $\begin{array}{l}\text { Randomized: no improvements in } \\
\text { any outcome }\end{array}$ \\
\hline & & ACQ & $\begin{array}{l}\text { Open label: improved overall } \\
\text { asthma symptoms and AQL } \\
\text { score at end of prescription that } \\
\text { persisted after prescription } \\
\text { (improvements maximal at the } \\
\text { 9-month study point) }\end{array}$ \\
\hline
\end{tabular}

*Other than for safety and logistics.

ACQ, asthma control questionnaire; ARI, acute respiratory illness; AQL, asthma quality of life; BHR, bronchial hyperresponsiveness; Cpn, Chlamydia pneumoniae; ECP, eosinophil cationic protein; $\mathrm{FEV}_{1}$, forced expiratory volume in 1 second; ICS, inhaled corticosteroid; Ig, immunoglobulin; IL, interleukin; LRTi, lower respiratory tract illness; Mpn, Mycoplasma pneumoniae; NNT, number needed to treat; PCR, polymerase chain reaction; PEF, peak expiratory flow.

allocated to placebo discontinued study medication because of side effects. Compared with placebo, subjects taking azithromycin (randomized and OL combined) reported significantly more nausea (33\% vs $9 \%$ for placebo), stomach pain ( $42 \%$ vs $12 \%$ for placebo), and diarrhea ( $42 \%$ vs $15 \%$ for placebo). The majority of these side effects were mild to moderate in severity and no subject taking azithromycin (either randomized or OL) reported discontinuation because of side effects. There were no significant differences in side effect frequency or severity when the arm ran- domized to azithromycin was compared with the cohort that elected OL azithromycin (Table 4).

\section{Discussion}

We found no significant treatment effect for subjects randomized to azithromycin. Our a priori power calculations were based on overall asthma symptom results from a previous pilot study that did not experience self-exclusion of patients with severe asthma, and in this study we were unable to demonstrate any statistically significant effects of 
treatment on overall asthma symptoms. We found a $15 \%$ difference in AQL score of $\geq 1$-unit improvement favoring azithromycin $(\mathrm{NNT}=7)$ at 12 months that was not statistically significant (Table 3 ). Because a change in AQL score $\geq 1$ represents an important clinical improvement, we advocate future azithromycin effectiveness trials of patients with mild to moderate asthma that are adequately powered to detect, at a minimum, an NNT of 10 to 20 for this chronic, morbid, and expensive condition.

The participants in the OL cohort had more severe asthma than those randomized to azithromycin, and their asthma was often refractory to guideline treatment. The OL cohort demonstrated statistically and clinically significant benefits that largely persisted at 12 months compared with placebo treatment. Six months after completing azithromycin, the OL cohort experienced a $21 \%$ improvement in overall asthma symptoms, a 1.8 -unit (26\%) improvement in AQL score and a 1.2-unit (20\%) improvement in asthma control score. This AQL score change was more than 3 times greater than the minimal clinically important change ( 0.5 units) and exceeded the threshold (1.5 units) for a large change. ${ }^{14}$ These azithromycin treatment benefits are greater and of longer duration than those achieved by current guideline treatments. For example, a recent efficacy trial in nonsmoking adults with uncontrolled asthma achieved lower benefits (1) when inhaled steroid dose was doubled (0.05 AQL questionnaire units, 0.03 asthma control units); (2) when the long-acting bronchodilator salmeterol was added (0.28 AQL questionnaire units, 0.31 asthma control units); or (3) when tiotropium was prescribed $(0.15 \mathrm{AQL}$ questionnaire units, 0.22 asthma control units). ${ }^{15}$ In AZMATICS, treating only 2 OL subjects with azithromycin was required to achieve an AQL score improvement of 1 unit or greater in one of them $(\mathrm{NNT}=2)$ at 9 months. Because $80 \%$ of asthma morbidity and health care utilization is experienced by patients with the most severe forms of the disease, ${ }^{16}$ our results suggest that azithromycin therapy may be a promising novel intervention to decrease the burden of morbidity and cost associated with management of severe and uncontrolled adult asthma, and future blinded, randomized trials are warranted.

\section{Previous Studies}

Ten randomized controlled trials of second-generation macrolides/azalides (azithromycin, clarithromycin, and roxithromycin) for chronic stable asthma have been published (see Tables 5 and 6 for more details). ${ }^{17-26}$ A 2005 Cochrane review concluded that there was insufficient evidence to confirm or refute the role of macrolide treatment in chronic asthma. ${ }^{1}$ Since 2005,3 additional trials of macrolides in chronic adult asthma have reported patient-oriented outcomes. ${ }^{22,24,26} \mathrm{Hahn}$ et al ${ }^{22}$ (our pilot) performed a practice-based effectiveness trial that included mainly patients with mild to moderate asthma who were randomized to 6 weekly doses of azithromycin or placebo. Outcomes of interest included asthma symptoms, AQL, and levels of $C$. pneumoniae-specific antibodies up to 3 months after the completion of treatment. Azithromycin treatment had a significant effect on asthma symptom reduction during the treatment phase, which persisted through study termination 3 months later. Elevated levels of $C$. pneumoniae-specific immunoglobulin A antibodies predicted worsening of asthma symptoms. ${ }^{22}$ AQL improved by 0.25 units, but the change was not statistically significant. Simpson et $\mathrm{al}^{24}$ performed an efficacy trial in nonsmoking adults with severe refractory asthma who were randomized to 8 weeks of clarithromycin or placebo and were followed for an additional 4 weeks after treatment. Clarithromycin treatment significantly improved AQL at the end of treatment (median AQL questionnaire score at baseline, 5.5; median score at end of treatment, $6.2 ; P=.01$ ). The improvement was more pronounced in subjects with "noneosinophilic" ("neutrophilic") asthma and waned 4 weeks after treatment. ${ }^{24}$ Sutherland et $\mathrm{al}^{26}$ performed an efficacy study that included bronchoscopic polymerase chain reaction (PCR) testing for $C$. pneumoniae and $M$. pneumoniae in a highly selected group of mild to moderate asthmatics who were randomized to 16 weeks of clarithromycin or placebo without observation after treatment. Clarithromycin treatment did not improve overall asthma control at the end of treatment. The PCR-positive subgroup had weak evidence $(P=.06)$ of a more rapid achievement in asthma control score $\geq 0.5$ units (the minimal important clinical difference). This study excluded subjects older than 60 years, those with severe asthma, smokers, those with coexisting chronic obstructive pulmonary disease (COPD), and any pa- 
tient with more than 2 exacerbations or respiratory tract infections before study entry (http://www. clinicaltrials.gov/ct/show/NCT00318708?order = 2). Each of these exclusion characteristics is associated with biomarkers of $C$. pneumoniae infection. ${ }^{27-31}$ These exclusions probably explain the detection of fewer atypical pathogens than anticipated (13\% PCR positive compared with an expected $50 \%){ }^{26}$ AZMATICS included at least 53 asthma subjects $(55 \%)$ who would have been excluded from typical asthma efficacy trials such as that of Sutherland et $\mathrm{al}^{26} ; 15 \%$ of AZMATICS subjects were aged 60 years or older; $24 \%$ had severe persistent asthma; $11 \%$ were current smokers; $25 \%$ had a history of 10 or more pack-years of cigarette use; and $15 \%$ had coexisting COPD.

AZMATICS' OL results are consistent with Simpson et $\mathrm{al}^{24}$ for subjects with severe asthma in that they demonstrate a significant benefit after macrolide treatment and are unique among all studies of macrolide treatment for asthma (see Tables 5 and 6) in that they demonstrate persistent benefits 1 year after treatment. Outcomes of the AZMATICS study also support findings of Hahn et $\mathrm{al}^{22}$ and Sutherland et $\mathrm{al}^{26}{ }^{26}$ who reported lesser or no benefit associated with macrolide treatment in subjects with mild to moderate asthma. However, all 3 studies were underpowered to detect clinically significant effects in milder asthma.

\section{Treatment, Side Effects, and Serious Adverse Events}

We chose azithromycin over other macrolides, including clarithromycin, because it has (1) unique pharmacodynamic properties that allow weekly dosing to maintain high intracellular drug levels, (2) few drug interactions, and (3) a good safety profile that has been demonstrated in more than 5000 adults in previous trials. ${ }^{32,33}$ A recent trial of daily azithromycin for 1 year in patients with COPD actually found a lower incidence of macrolide-resistant oral pathogens in the azithromycin-treated arm compared with the placebo arm, alleviating concerns about antibiotic resistance. ${ }^{34,35}$ An additional benefit is that, unlike clarithromycin, azithromycin has no residual taste that might compromise blinding in some subjects. The cumulative azithromycin doses in the randomized and OL arms (8400 mg vs $9750 \mathrm{mg}$, respectively) differed somewhat, but both treatment regimens resulted in equally effective and prolonged intracellular con- centrations of azithromycin. ${ }^{36}$ Side effects were generally mild and of similar frequency for both doses (Table 4), and no serious adverse events or discontinuations because of side effects were attributed to either azithromycin regimen.

\section{Mechanism of Action}

Our trial did not directly address mechanism of action. AZMATICS was designed to distinguish between effects that wane (consistent with direct anti-inflammatory mechanisms) or persist (consistent with antimicrobial mechanisms) after completion of treatment. We interpret the residual benefits found in OL subjects to be most consistent with an antimicrobial mechanism of action.

\section{Limitations}

This trial has several limitations, including the absence of biomarkers for atypical infections and follow-up pulmonary function testing (PFT). Lack of PFT precluded the comparison of objective measures of airway function with the patient-oriented clinical outcomes and decreased our sample size by excluding enrollment of otherwise-eligible patients (Figure 1). Importantly, AZMATICS was underpowered to detect clinically important improvements in subjects with mild to moderate persistent asthma. Our sample was limited to subjects with Internet access, was deficient in minority representation, and did not standardize asthma treatment across groups.

Our proportion lost to follow-up exceeded 20\% at year 1 , which lowered the quality of our trial from a level 1 to a level 2 study, according to the Strength of Recommendation Taxonomy, a standard adopted by many primary care publications. ${ }^{37}$ The placebo control group (with milder asthma) and the OL cohort (with more severe asthma) did not have comparable asthma prognoses. Because asthma prognosis is generally worse for severe asthma, this disparity could have diminished contrasts (ie, tendency to bias the OL results toward a null effect). By necessity, the OL cohort subjects were not blinded to azithromycin allocation. If placebo effects are accepted as an explanation only during the time period of medication administration, then placebo effects cannot be invoked as an explanation for peak benefits that occurred 6 months after completing azithromycin treatment. It is possible that other mechanisms, such as denial, cognitive dissonance, or both, could have promoted 
systematic misreporting by OL subjects. A true treatment effect is supported by the strength and consistency of the results (including 2 validated instruments, the $\mathrm{AQL}$ questionnaire and the asthma control questionnaire), by agreement with our blinded pilot results ${ }^{22}$ and by the results of the principal investigator's (DLH) previous prospective observational cohort study that included patients with confirmed C. pneumoniae infections. ${ }^{38}$ Although exploratory analyses suggest that smoking may have a significant modifying effect, AZMATICS was underpowered for subgroup analyses. Future studies should be powered for robust subgroup analyses, which can be performed only if the subgroups are enrolled rather than systematically excluded from enrollment.

\section{The Importance of Effectiveness Studies of Asthma}

A technology assessment commissioned by the National Asthma Education Panel states that "short-term drug efficacy studies are over-represented in the present literature." 39 Standard exclusion criteria in adult asthma efficacy trials include restricted age ranges, pulmonary function parameters, current and previous smoking, and lung comorbidities such as coexisting COPD. ${ }^{4,5}$ As a result, $95 \%$ of asthma subjects have been systematically excluded from the trials used to support guideline recommendations. ${ }^{4,5}$ Thus, asthma efficacy trials and the guidelines derived from them may not generalize well to the broader population of asthma sufferers.

To address some of the limitations of asthma efficacy studies, AZMATICS was designed as a "pragmatic" or "practical clinical trial" to include a diverse population of study participants, recruitment of participants from different practice settings, and a range of health outcomes. ${ }^{40,41} \mathrm{We}$ enrolled subjects from community-based practices and applied exclusion criteria that were solely based on safety and logistic considerations (eg, the ability to complete the study). Furthermore, AZMATICS is, to our knowledge, the first trial to include an OL arm for subjects with severe asthma who otherwise would have been excluded based on patient preference. Using this approach, we succeeded in enrolling 1 of 3 screened patients; we probably would have been able to enroll closer to 1 in 2 screened patients had funding to perform PFT been available (Figure 1). Our actual enrollment (30\%) and potential enrollment (50\%) experience exceeds the $5 \%$ enrollment average for asthma efficacy trials. ${ }^{5}$ Future larger pragmatic trials may achieve even higher enrollment proportions by using physiciandiagnosed asthma as the primary eligibility criterion and using PFTs as a baseline covariate and an outcome measure but not as an additional eligibility criterion.

\section{Conclusions}

This randomized trial of 12 weekly doses of azithromycin failed to demonstrate statistically significant improvements after 1 year in any of the patient-oriented outcomes that we evaluated. Interpretation is complicated because a significant number of eligible asthma subjects-who had greater than average severity of the disease-declined to be randomized. Azithromycin treatment was well tolerated overall, and in the OL group with more severe, often refractory asthma, there seemed to be persisting substantive, clinically significant benefits to asthma symptoms, AQL, and asthma control for at least 6 months in about half of treated subjects. We advocate further effectiveness trials of persistent asthma of all severity categories that include an array of biomarkers to allow for secondary subgroup analyses, the results of which might favor one biological mechanism over another. However, at this time we do not favor approaches that insist on making a microbiologic diagnosis before randomization ${ }^{26}$ or treatment, ${ }^{42}$ as advocated by others, because this approach inevitably excludes patients who are unable to undergo or tolerate bronchoscopy. Future cost-effectiveness studies may help to determine whether making a microbiologic diagnosis via bronchoscopy versus treatment of all severe refractory asthma patients (especially given the NNT suggested by this study) is the more cost-effective approach.

Pending further randomized trials and given the relative safety of azithromycin and the significant disease burden from severe refractory asthma, prescribing prolonged azithromycin therapy to patients with uncontrolled asthma may be considered by managing clinicians, particularly for patients who have failed to respond to conventional treatment and as an alternative to instituting immunomodulatory agents.

We gratefully acknowledge the voluntary participation of the Data Safety Monitoring Committee (DSMB): Dr. David 
DeMets (chair) and Dr. David Rabago. We also thank Dr. Jon Temte for suggesting the use of Internet data collection. We gratefully acknowledge the voluntary participation of the study subjects and the following clinicians and staff who enrolled them: the AAFP National Research Network: Dr. Ed Bujold, Dr. Melissa Devalon, Debbie Graham, Dr. Steve Mattson, Dr. Andrew Pasternak, and Dr. Elisabeth Spector; the Ambulatory Network for Scholarship and Research: Dr. Keith Knepp and Dr. Gregg Stoner; the Cleveland Ambulatory Research Network: Dr. Sandra Snyder and Dr. Chris Young; the Marshfield Clinic: Dr. Jeremy Bufford, Gloria Cornelius, and Dr. Steven Yale; the Oklahoma Physicians Resource/Research Network: Dr. Cheryl Aspey, Eileen Merchen, Katy Duncan-Smith, Emily Teasdale, and Crystal Turner; and the Wisconsin Research and Education Network: Dr. Elizabeth Bade, Dr. Jennifer Frank, Dr. Dan Jarzemsky, Dr. Cheri Olson, Therese Pedace, Katherine Pronchinske, and Dr. Ayaz Samadini.

\section{References}

1. Richeldi L, Ferrara G, Fabbri LM, Lasserson TJ, Gibson PG. Macrolides for chronic asthma. Cochrane Database Syst Rev 2005;(3):CD002997.

2. Altenburg J, de Graaff CS, van der Werf TS, Boersma WG. Immunomodulatory effects of macrolide antibiotics - part 1: biological mechanisms. Respiration 2011;81:67-74.

3. Johnston SL, Martin RJ. Chlamydophila pneumoniae and Mycoplasma pneumoniae. A role in asthma pathogenesis? Am J Respir Crit Care Med 2005;172: $1078-89$.

4. Herland K, Akselsen J-P, Skjønsberg OH, Bjermer L. How representative are clinical study patients with asthma or COPD for a larger "real life" population of patients with obstructive lung disease? Respir Med 2005;99:11-9.

5. Travers J, Marsh S, Williams M, et al. External validity of randomised controlled trials in asthma: to whom do the results of the trials apply? Thorax 2007;62:219-23.

6. Demoly P, Gueron B, Annunziata K, Adamek L, Walters RD. Update on asthma control in five European countries: results of a 2008 survey. Eur Respir Rev 2010;19:150-7.

7. Global Initiative for Asthma (GINA) 2007. Global Strategy for Asthma Management and Prevention. Updated 2007. GINA Executive Committee, 92 pages.

8. American Thoracic Society. Lung function testing: selection of reference values and interpretive strategies. Am J Resp Dis 1991;144:1202-18.

9. Dekker FW, Schrier AC, Sterk PJ, Dijkman JH. Validity of peak expiratory flow measurement in assessing reversibility of airflow obstruction. Tho$\operatorname{rax} 1992 ; 47: 162-6$.

10. Juniper EF, Buist AS, Cox FM, Ferrie PJ, King DR. Validation of a standardized version of the Asthma Quality of Life Questionnaire. Chest 1999;115: 1265-70.

11. Juniper EF, O'Byrne PM, Guyatt GH, Ferrie PJ, King DR. Development and validation of a ques- tionnaire to measure asthma control. Eur Respir J 1999;14:902-7.

12. Juniper EF, O'Byrne PM, Roberts JN. Measuring asthma control in group studies: do we need airway calibre and rescue beta2-agonist use? Respir Med 2001;95:319-23.

13. Hahn DL. An unanticipated effect of clinical trial registration. BMJ [serial online] Available from: http://www.bmj.com/content/325/7376/1314?tab= responses, 2007. Accessed April 27, 2012.

14. Juniper EF, Guyatt GH, Willan A, Griffeth LE. Determining a minimal important change in a disease-specific quality of life instrument. J Clin Epidemiol 1994;47:81-7.

15. Peters SP, Kunselman SJ, Icitovic N, et al. Tiotropium bromide step-up therapy for adults with uncontrolled asthma. N Engl J Med 2010; 363:1715-26.

16. Smith DH, Malone DC, Lawson KA, Okamoto LJ, Battista C, Saunders WB. A national estimate of the economic cost of asthma. Am J Resp Crit Care Med 1997;156:787-93.

17. Shoji T, Yoshida S, Sakamoto H, Hasegawa H, Nakagawa H, Amayasu H. Anti-inflammatory effect of roxithromycin in patients with aspirin-intolerant asthma. Clin Exp Allergy 1999;29:950-6.

18. Amayasu H, Yoshida S, Ebana S, et al. Clarithromycin suppresses bronchial hyperresponsiveness associated with eosinophilic inflammation in patients with asthma. Ann Allergy Asthma Immunol 2000; 84:594-8.

19. Black PN, Blasi F, Jenkins CR, et al. Trial of roxithromycin in subjects with asthma and serological evidence of infection with Chlamydia pneumoniae. Am J Respir Crit Care Med 2001;164:536-41.

20. Kraft M, Cassell GH, Pak J, Martin RJ. Mycoplasma pneumoniae and Chlamydia pneumoniae in asthma. Effect of clarithromycin. Chest 2002;121: 1782-8.

21. Kostadima E, Tsiodras S, Alexopoulos EI, et al. Clarithromycin reduces the severity of bronchial hyperresponsiveness in patients with asthma. Eur Respir J 2004;23:714-7.

22. Hahn DL, Plane MB, Mahdi OS, Byrne GI. Secondary outcomes of a pilot randomized trial of azithromycin treatment for asthma. PLoS Clin Trials 2006;1:e11.

23. Piacentini GL, Peroni DG, Bodini A, et al. Azithromycin reduces bronchial hyperresponsiveness and neutrophilic airway inflammation in asthmatic children: a preliminary report. Allergy Asthma Proc 2007;28:194-8.

24. Simpson JL, Powell H, Boyle MJ, Scott RJ, Gibson PG. Clarithromycin targets neutrophilic airway inflammation in refractory asthma. Am J Respir Crit Care Med 2008;177:148-55.

25. Strunk RC, Bacharier LB, Phillips BR, et al. Azithromycin or montelukast as inhaled corticoste- 
roid-sparing agents in moderate-to-severe childhood asthma study. J Allergy Clin Immunol 2008; 122:1138-44.

26. Sutherland ER, King TS, Icitovic N, et al. A trial of clarithromycin for the treatment of suboptimally controlled asthma. J Allergy Clin Immunol 2010; 126:747-53.

27. von Hertzen L, Vasankari T, Liippo K, Wahlström E, Puolakkainen M. Chlamydia pneumoniae and severity of asthma. Scand J Infect Dis 2002;34:22-7.

28. Hahn DL, Golubjatnikov R. Smoking is a potential confounder of the Chlamydia pneumoniae-coronary artery disease association. Arterioscler Thromb 1992;12:945-7.

29. Pasternak R, Huhtala H, Karjalainen J. Chlamydophila (Chlamydia) pneumoniae serology and asthma in adults: a longitudinal analysis. J All Clin Immunol 2005;116:1123-8.

30. Brandén E, Koyi H, Gnarpe H, Tornling G. Chronic Chlamydia pneumoniae infection is a risk factor for the development of COPD. Respir Med 2005;99:20-6.

31. Hahn DL. Infectious asthma: a reemerging clinical entity? J Fam Pract 1995;41:153-7.

32. Grayston JT, Kronmal RA, Jackson LA, et al. Azithromycin for the secondary prevention of coronary events. N Engl J Med 2005;352:1637-45.

33. O'Connor CM, Dunne MW, Pfeffer MA, et al. Azithomycin for the secondary prevention of coronary heart disease events: the WIZARD Study: a randomized controlled trial. JAMA 2003;290: 1459-66.
34. Albert RK, Connett J, Bailey WC, et al. Azithromycin for prevention of exacerbations of COPD. N Engl J Med 2011;365:689-98.

35. Hahn DL. Azithromycin for prevention of exacerbations of COPD. N Engl J Med 2011;365:2235-7.

36. Schentag JJ, Ballow CH. Tissue-directed pharmacokinetics. Am J Med 1991;91:5S-11S.

37. Ebell MH, Siwek J, Weiss BD, et al. Strength of recommendation taxonomy (SORT): a patient-centered approach to grading evidence in the medical literature. J Am Board Fam Pract 2004;17:59-67.

38. Hahn DL. Treatment of Chlamydia pneumoniae infection in adult asthma: a before-after trial. J Fam Pract $1995 ; 41: 345-51$.

39. Aronson N, Lefevre F, Piper M, et al. Management of chronic asthma. Evidence report/technology assessment number 44. AHRQ publication no. 01E044. Rockville, MD: Agency for Healthcare Research and Quality; 2001.

40. Tunis SR, Stryer DB, Clancy CM. Practical clinical trials. Increasing the value of clinical research for decision making in clinical and health policy. JAMA 2003;290:1624-32.

41. Thorpe KE, Zwarenstein M, Oxman AD, et al. A pragmatic - explanatory continuum indicator summary (PREVIS): a tool to help trial designers. J Clin Epidemiol 2009;62:464-75.

42. Rollins DR, Beuther DA, Martin RJ. Update on infection and antibiotics in asthma. Curr Allergy Asthma Rep 2010;10:67-73. 